den tradition som startade med de ryska formalisterna, förlängdes in i väst med Roman Jakobson och billade grund för de franska strukturalisterna Barthes och Greimas. Och Jag vet ingen vetenskapsgren från 1900-talet som varit mer engagerad att utreda konstens och poesins väsen son den.

Och fragan är om inte detta misstag vilar på ett som är ännu mer grundläggande. Havskov Jensen drar nämligen en dogmatisk gräns mellan det hon kallar den logiska empirismens symbolbegrepp (Carnap, Wittgenstein, Russel1) och det icke-diskursiva symbolbegrepp som hon hämtat från främst susanne Langer. I och för sig är det en viktig distinktion men den far olyckliga konsekvenser när den samtidigt programnatiskt och utan betänkligheter överfös till verbalsprak respektive bild. Det finns ej năgon sådan självklar åtskillnad mellan dessa två uttryckssätt. Och de kan aärför lika lite hänvisas till et självklart antingen eller 1 hjärnans tva heimisfärer.

Det potiska tänkandet och skapandet är kanske det bästa exemplet på detta eftersom de bygger mer på associativa och paradigmatiska kopplingar än logiska och syntagmatiska. Visuella fenomen har mer med det förra att göra medan tal och framför allt text i prosaform är beroende av det senare. Să langt är det med stor sannolikhet korrekt. Men gränsen är inte definitiv och det gäller även för barnens sätt att uttrycka sig visuellt eller verbalt. Och av den anledningen àr det mer fruktbart att se băde den mänskliga kommunikationen och barnens uttrycksbehov som en helhet. I det samanhanget menar jeg att man kan ha god hjälp av en humanistisk semiotik som kan visa vägar till săväl pătagliga överensstämelser som väsentilga skilinader mellan visuella och vexbala uttrycksmedel.

Gert $z$ Nordström er professor ved Konstfackskolan i Stockholm 


\section{Massekommunikation er kommet i gymnasiet - eller er det?}

\section{Af Claus Westh}

Hothe muligheder tigger der t gymasiet for urdervisning $i$ masekommutkation?

Claus Westh reflekterex over de fagtige og padagogiske muZigheder. Med udgangspunkt $i$ den kommende bekendtgratse gennemgar han nogle af mulighedeme i danskfaget. Har giver

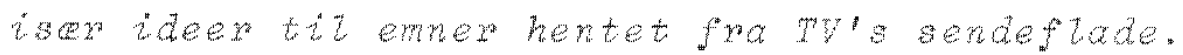
Clams Weath kaster ogsa et bztk pa de andre fag og pam migm hederre for tverfagtigt samarbejde.

Hans korkzusion ex at der ep muligheder, men elevernes banlede beskeftigelse med masekommikation i lobet af gymasiats tre ar kan godt ga hen og blive meget minimal.

Gymnasiets danskfag skal have ny bekendtgфrelse. Selv om initiativet til dette nok har haft kulturarven som sin storste interesse, er der dog 1 ajourforingen af faget ogsa sket det at massekommunikation har faet sin plads 1 danskundervisningen. Det er for sa viat ikke noget nyt. Siden "det brede tekstbegreb" blev knasat i begyndelsen af $70^{\circ}$ erne har man kunnet undervise 1 alle sider af massekommunikationen 1 Dansk.

Det nye er at nu er det obligatorisk. Ikke med nogen overvaldende vagt, nemlig kun et halvt semester ud af de seks, 24-30 timer, men dog så meget at alle elever i gymasiet nu vil fa sig en porm tion mediekundskab, og også så meget at massekommunikation skal figurexe til eksamen med et par sporgsmăl. Det vil måske vise sig 
at vare den afgorende sikring af en udvikling inden for feltet. At indf $\phi r e$ eksamen $i$ noget ex sjaldent progressivt. Men der er nok ingen tvivl om at nar massekomunikationsundervisningen indtil nu ikke har faet den store udbredelse ad frivillighedens vej, skyldes det at lareme har folt sig meget forpligtede over for det stof som man har betragtet som obligatorisk eksamensstof.

Det noget begransede omfangskrav skal forstas under to vinkler. For det forste betyder det at alle larere kan klare det uden at komme i store faglige vanskeligheder, og for det andet er det for den interesserede larer log klasse) muligt at lase mere massekommunikation under det som hedder "selvvalgte studiemonstre" $i$ den nye bekenatgorelse.

Rammerne for undervisningen er 1 ovrigt brede. Bekendtgorelsens formulering lyder saledes:

"Undervisningen 1 massekommunkation skal skæxpe elevernes oplevelsesevre og kxitiske indsigt gennem arbejdet med delonrader inden for især nyeste tias massekommunikation og med massemediernes betydning for bevidsthedsdannelsen efter 2. verdenskrig. Massekommunikationen kan også indarages i forbindelse med den historiske lasning".

I vejledningen hedaer det udaybende:

"I massekommunikationsundervisningen kan der inden for både fiktion, ikke-fiktion og blandingsformer heraf arbejdes med de elektroniske medier (radio, TV, video), film og de trykte medier (dag- og ugepressen, serieblade og -bøger). Der kan arbejdes med genrer som nyheds- og aktualitetsformer, underholdningsformer og radiospil, med emnex som mediestruktur, medieforbrug og mediexstetik, narradio, lokal-TV.

undervisningen kan tilrettelagges son selvstwndige forlфb, integreret med fagets andre stofområder ellex i samarbejde med andre fag. Praktisk arbejde med produktion inden for de forskellige medieformer kan indarages.

Inden for den samlede massekommunikation har ikke mindst billedmedierne, og her igen især de elektroniske, en storre og storre betydning for opfattelsen af verden. Denne del af den samlede massekommunikation må derfor påkalde sig en sarlig interesse 1 undervisningen".

Som man kan se ex der ikke lagt hindringer i vejen for nogen. Massekomunikation ex forstaet $i$ en meget bred betydning. I nogle passager kunne man måske mene for bred. Nar man navner områder som film, sexieblade og bøger og radiospil ex man vel i virkeligheden inde $i$ det litterare felt, hvor der principielt ikke 
er nogen forskel pa at arbejde med et radiospil og en novelle, eller en film og en roman, ellex triviallitteratur og skonlitteratur.

Man har heller ikke foretaget en skarp afgransning til andre fag. Mediestruktur og medieforbrug vil vare lige sa naturlige momenter 1 Samfundsfag. Et par holdningsmarkфrer i teksten er vigtige at bemarke sig. I bekendtgprelsens forste satning tales bade om oplevelsesevne og kritisk indsigt. Heri ligger en opfattelse af at massemedierne ogsa er positive tilskud til vores verden og ikke blot misliebige forforelsesmidier. En anden mark $\phi r$ ligger $i$ vejledningens sidste setninger. En kraftig anbefaling af at beskaftige sig med de elektroniske billedmediex (las: TV).

Man kan måske spфrge sig selv om "oplevelsesevne" er et helt heldigt valgt ord. Hvis det indebarer en exkendelse af at tv-produktion 1 sig selv er en kunstart - sadan som den kan praktiseres fx 1 nyheds-, aktualitets- og underholdningsudsendelser - sa ex det fint. Hvis ordet derimod far folk til at tanke $i$ retning af TV-teater, video-kunst m.v. er det efter min mening for snavert.

\section{Didaktiske overvejelser}

Hvad er målene for undervisning $i$ massekommunikation?

Malet for undervisningen er at $\phi g e$ elevernes bevidsthed om mediernes funktion i samfundet og deres betyaning for den enkeltes bevidsthedsdannelse. Malet er ikke kun at gøre eleverne til kritikere af medierne, men ogsa til brugere. St申rstedelen af danske gymnasie- og hf-elever bruger medierne for 11 dt. Det vil sige at de ikke betragter aem som en vardifuld kilde til at lare mere om ongivelserne og sig selv.

I den almindelige mediediskussion taler man ofte om at born og unge ser for meget fjernsyn. Det er efter min mening et for enkelt syn pa sagen. Man kan med lige sa stor ret sige at de ser for lidt fjernsyn, nar man derved tanker pa deres muligheder for at orientere sig $i$ samfundet. Det samme forhold gor sig galdende ved aviser. Man kan godt sige at et vigtigt formal for undervis- 
ningen ex at give eleverne et kritisk brugerforhold til medierne. Naturligvis vil det ogsă vare et vardigt formăl at fa eleverne til at bruge medieme ved at udtrykke sig gennem dem, 1 skrift, lyd eller billeder, men det mal ligger lidt langere ude. I denne forbindelse taler vi ikke om at benytte fjernsyn og radio som kunstnexiske medier der producerer dramatik og film m.m. Denne side af medierne ex selvfolgelig ogsa vasentlig og her er ogsa vigtige oplevelser at hente, men fagdidaktisk set ligger problemstillingerne blot $i$ forlengelse af de traditionelle problemer som er knyttet til litteraturlasningen.

Selv om begrundelsen for at behandle massemedierne i skolen kan synes indysende pga. dexes aktualitet og udbredelse, sa er det ikke sadan at man slipper for motivationsproblemer nar man gar igang med arbejdet. Problemerne kan have forskellig baggrund. Et af dem kan stamme fra den almindelige og misforstaede despekt for medierne. Dot er ikke "fint" at bruge tid pa dem. Man traffer jo jæunligt voksne der bryster sig af at de ikke ser TV. De synes ikke det ex lodigt medium. Den let snobbede holdning finder man ogsa hos elever. De har lart at Romanbladet, Ekstra Bladet $o g$ TV er under niveau, og selv om de măske er storbrugere af alle medier vil de nodigt sta ved det. De sa at sige skammer sig over deres "last".

En anden holdning viser en stor naivitet over for mediene, specielt billedmedierne. Når man har set billeder af en sag hax man set sandheden on sagen, og det er der ingen grund til at sætte spørgsmålstegn ved.

Hos Iærere kan man se begge disse holdninger. Markvardigt nok også den siastnavnte. Tilliden til billedet som sandhedsviane er stor. At en del lærere ikke betragter tv-mediet som sa lodigt som bogstavet og bogen er knap så overraskende, men ikke minare beklageligt. Men hvis vi ser bort fra denne - ikke helt uvasentlige - tilstand, sa har dansklarerne gode forudsatninger for at kaste sig ud i massekomunikationsundervisning. En stor del af undervisningen kan baseres pă dansklaxerens grundfærdigheder. Det det drejer sig on er jo i vid udstrakning at lase tekster. Det 
drejer sig om at lave sprogbrugsanalyser, at analysere symbolsprog, at lase ideologikxitisk og at lase med forstăelse for bevidsthedshistorien.

Men naturligvis må man ogsa oparbejde ny viden og nye metoder, som dog altsammen Iigger tat pä det dansklarexen i forvejen kan. Der skal oparbejdes en viden om mediestrukturen $i$ Danmark, kendskabet til journalistiske arbejasformer og genrer skal фges, det samme galder redaktionsprincipper. De fleste dansklærere har i de senere år oparbejdet en fardighed $i$ billedlasning, den skal videreudvikles til axbejdet med levende billeder og $i$ den forbindelse ex kendskab til fortællestrukturer fra litteraturen en væsentlig ballast.

\section{Forslag til undervisning}

I den massekommunikationsundervisning der har varet drevet indtil nu, har der varet stor interesse for at arbejde med forskellige serier som Dallas og Dollars. Metoden her er meget lig den som benyttes ved arbejdet med den trykte triviallitteratur.

Den side af massemedieme er det selvfølgelig stadig pa sin plads at tage op. Personligt synes jeg at det ex mere spendende at arbejde med andre genrer, lidt fjemere fra den traditionelle litteraturlasning. Ikke mindst synes jeg det er vigtigt at arbejde med nyheds-og aktualitetsstoffet.

En rimelig indfaldsvinkel til arbejdet med IV's nyheds- og aktualitetsuasendelser er at begynde med aviser. Her kan man pa en overskuelig made $f a$ arbejdet sig ind pa elementare begreber som nyhedskriterier, redaktionsprincipper, selektion, journalistik, elementar billedanalyse og der kan blive gode muligheder for et solidt arbejde med sproget i medierne.

Materialerne hentes fra såvel landsdækkende som lokale aviser. Det er ikke darligt hvis man kan fa fat pa sakaldte alternative aviser. Kontrastopstillinger er under alle onstandigheder gode til at arbejde sig på selektions- og redaktionsprincipper. 
Det burde vare et naturligt led $i$ al medieundervisning at man arbejdede med nyhedsformidingen i skolens lokalomrade. I en hel del tilfalde vil det kunne give en god historisk fomemmelse at arbejde med lokalpressens historie. Fra firebladssystemet til den "uafhangige" regionalavis.

En "eye-opener" kan det vare at beskaftige de husstandsomdelte lokalblade. Mange elever har et forbloffende "uskyldigt" forhold til aisse blade. Arbejdsformen ved arbejdet med de lokale presseforhold kan med fordel vare projektarbejdet. Her ex mange muligheder for at stille de basale sporgsmal: "Hvad skal vi tage fat pa?" "Hvordan skal vi afgranse emnet?" "Hvordan skal vi tilrettelagge arbejdet?" I arbejdet vil mange forskeli1ge arbejasformer kunne indga. En af de oplagte, stadig lidt utraditionelle er interviewet. Altsa: Ud at tale med folk, både lokalpressens forbrugere og dens producenter. Selvstendig journalistisk virksomhed kan det blive til, hvis man kan komme ud at overvare noget af det samme som den lokale avis overvarex. Det kan vare moder, begivenheder af forskellig slags, personer i centrum for en diskussion o.m.a. Bevidstheden om mediearbejde vil stige kraftigt gennem en sdan proces! Som afslutning pa et forlob er det en oplagt ide at invitere reprasentanter for lokalpressen ind $i \mathrm{klasseva-}$ relset til en diskussion!

En indforing i arbejdet med TV's billedside kan begynde med et arbejde med enkeltbilleder, fx pressefotos uden undertekster. Opgaven bestar $i$ at forskellige elever satter undertekster pa de samme billeder. Man vil derved opdage hvor afhangig billediasningen er af konteksten. Billedet selv siger altsă ikke sand-m heden!

Et videre arbejde kan føre til ikonografisk forståelse. Hvordan præsenterer forskellige udsendelsestyper sig? Sat Sфren Ryge Petersen over for Jprgen Mylius ellex Kim Schumacher. Havebrugsudsendelser over for Eldorado-typen. Soren Ryge Petersen optrader ufriseret, i gamnelt slidt arbejdstøj, gerne med en greb i" håden. Han udstraler soliditet, sagkundskab, "ved-jorden-atblive-danskhed", som hanger godt sammen med hans talent for at 
tale direkte til seerne som han umiddelbart komer pa bolgelangde

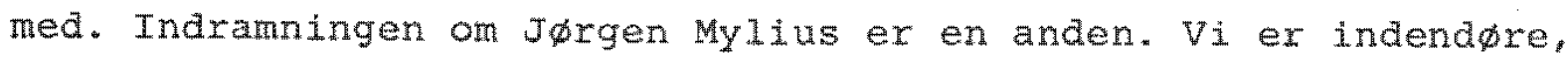
Jørgen Mylius har sit pane tøj på, altid jakke, en anelse nonchalance, ongivelserne er tydeligt et studie med den fascination der ligger i at se studieapparatur i baggrunden, starkt lys osv., eller det er restaurant" bar-miljфer. Der optrader næsten udelukkende smukke, festklædte, sexede personer omkring studievarten. Stemingen er international. Der kan vare samtaler med andre personer, men de er korte, overfladiske. varten kan også tale direkte til seerne, men han far ingen kontakt. Det er heller ikke meningen. Her er tale om envejskomunikation. Den overfladiske kontakt understreges af korte $1 \mathrm{yn}-\operatorname{smil}$ der flammer hurtigt op og forsvinder igen uden at have sat sig spor. Med søren Ryge Petersen og Mylius er to forskellige medieastetikker sat over for hinanden. Afhangig af emne og formal, naturligvis, men maske også af holdning.

Andre eksempler på tv-folks medieforstålse kan bruges. Poul Thomsen skaber bestemte ramer on sine udsendelser. Quizzer kan bruges på flexe madex, enten som en made at popularisere et stof pă, Piet van Deurs og Per Arnoldi kan vare eksemplex pă dette, eller de bruges for deres egen skyld som ren underholaning. Erling Bundgard er et eksempel pa dette. Iscenesættelsen af TVavisen, Sondagsavisen og Sporten er andre muligheder for pa en elementar made at trane elementar iagttagelse af tv-mediet.

En god ide vil det vare at indspille et antal af de faste tvprogrammers introduktioner pä et videoband. En gennemspilning af sădan et bånd fra ende til anden vil på en nem made vise eleverne hvor forskellige holdninger der ligger bag uasendelsesfladen og indsigten vil eleverne have faet gennem en ikonografisk anaIyse.

Ogsă andre genrer egner sig til elementar indførelse i tv-billedet. Et velegnet materiale dukker op hver gang der er folketingsvalg eller folkeafstemning. De sma ti-minutters film man benytter der indeholder ofte et vald af billedklicheer. De konservatives film ved sidste folketingsvalg var et helt katalog over sadanne 
klicheer. Socialdemokratiet og kristeligt Folkeparti havde hver deres udgave af "vor-populit"-klicheen. SF markerede sig som et puritanistisk parti ved at undgá den slags og vaxe bevidst kedelige 1 deres prasentation. VS var (naturligvis) studentikose 1 deres brug af TV-avis-kilicheen.

En sarlig lille genre er dukket op 1 DR $i$ de senere år: reklamespots on egne produktioner. Ogsa her vil man kunne analysere "selvforstålsen" Frem. En dyberegående analyse af tv-mediets made at formidle pa kan man gennemfore ved at arbejde med begrebet faktion (dannet af "fakta" og "fiktion"). I TV ex der $i$ de seneste ar sket en kraftig udvikling i retning af at benytte spillefilmens virkemidler ved reportager on virkelige forhold. Forskellige typer af billedklicheer benyttes sammen med underlagningsmusik og aramatisk komposition til at formidle et stof. Eksempler kan vare udsendelser af "Trigon"-typen eller de langere indslag 1 sфndags-avisen. Ret ofte kan det her vare svart at skelne fiktion og virkelighed fra hinanden. Genren hax mange lighedspunkter med "new-journalism"-begrebet. Formalet med analyserne er at fore eleverne hen til en oget mediebevidsthed, hvor der på baggrund af indsigt $i$ mediernes virkemidler opstår en diskussion om holdbarheden af det virkelighedsbillede medierne viderebringer.

\section{Elevproduktioner}

Blandt medieundervisere moder man ofte holdningen at en forudsetning for at eleverne kan fa et uabytte af undervisningen er at de selv producerer video og film. Hvis det standpunkt er rigtigt kan man lige sa godt lade vare med at tage emnet massekommunikation op $i$ Dansk med det timetal der er afsat til det. Et halvt semester med 3-4 timer om ugen rakkex ikke ret langt, hvis man skal lave gennemarbejdede produktioner.

Synspunktet er nok ogsa lidt forenklet. Man beder jo heller ikke eleverne skrive en roman for man underviser 1 romaner, eller komponere en symfoni for man tager det emne op i Musik. 
Men naturligvis er det rigtigt, at det har en stor padagogisk vardi selv at prove at bakse med kameraeme og mikrofonerne, og mindre $\phi v e l s e r$ af den art kan der da ogsa blive tid til.

Fx. kunne man godt forestille sig at eleverne forsфgte sig med produktion af nyhedsudsendelser fra skolens hverdag eller fra den narmeste omegn. To ting vil man sandsynligvis opdage: Hvor svart det er at klippe et stof til nar man kun har 10 minutter, og hvor svert det er at fylde 10 minuter ud. Begge situationer vil fore til vasentlige diskussioner om nyhedskriterier, selektionsprincipper m.v.

Kunne man $i$ en periode $i$ en klasse lave en ugentlig 10 minutters tv-avis om livet pa skolen? Lad os sige fire mandage i træk? Produktionen vises i et hjorne af frikvartersrumene for dem der har lyst til at se den.

\section{Historisk lesning}

Meget fornuftigt kraver den nye bekendtgørelse ikke at man arbejder med massekommunikation fra andet end nutiden. Mulighederne for at finde egnet stof er begransede nar man gar tilbage i tiden. En del massekommunikation foraldes hurtigere end skonlitteratur. Măske fordi interessen falder med interessen for emnet. Der skal en meget stor metabevidsthed til hvis man kun skal beskaftige sig med kommunikationsformen og ikke med indholdet, og dertil kommer at aviser der er 100 ar gamle er skrevet $i$ et sprog der ikke fanger hos nutidens unge. Men naturligvis kan det lade sig gore at undervise i tidigere tiders massekomunikation, og derigennem fa vigtige historiske pointer hjem. Omkring arhundredskiftet dukker firebladssystemet op. Det er der vigtige perspektiver $i, o g$ den berфmte skejby-ulykke indgar allerede i en del danskundervisning $i$ kraft af den behandling den fik $i$ aviser med forskellige politiske holdninger.

Bladdøden efter 2. verdenskrig er et handterligt emne og egnet til at satte et arbejde med de lokale presseforhold i et historisk perspektiv. Faktisk kan man jo ogsa se historisk pa nutiden 
og fremtiden, og der vil den aktuelle mediedebat give god baggrund for at $\phi g e$ den historiske bevidsthed.

\section{IV som selvstandig kunstart}

Synspunktet er overraskende for mange elever. Men det at lave tv kan faktisk betragtes som en kunstart i sig selv. Maske er det oven $1 \mathrm{k \phi bet}$ sadan at $v i 1$ Danmark har nogle af verdens bedste tv-kunstnere?

Det vil vare yderst rimeligt at arbejde med tv-kunstnere som Flindt Petersen og Exik stephensen, Båsgåd og Jorgen Pedersen, Poul Martinsen, Bo Damgara og John Carlsen, Poul Nesgård og Jarl Exis Mikkelsen. Alle sammen folk der har et overordentigt artistisk forhold til mediet og som bevidst arbejder for at forny genrerne. De fleste af dem har udtalt sig om deres tv-syn og deres måde at arbejde pä.

\section{Eksamen}

Siden 1971 har det faktisk varet muligt at bruge aviser, radio og TV til eksamen I Dansk. Mange har gjort det forste. Uendeligt f har benyttet de andre medier i den situation. Men det kan lade sig gфre og det har en meget positiv effekt pa undervisningen. En mulighed er $f_{x}$ at eksaminere $i$ TV-avisen. Man skal benytte to videoopstilinger, en $i$ forberedelseslokalet og en i eksamenslokalet. Eleven fax et enkelt indslag af TV-avisen at analysere. Det ma ikke vare mere end 5-6 minutter năr forberedelsestiden er en time. Som baggrund for analysen far han desuden en oversigt over de andre indslag 1 TV wavisen den dag. Det giver nu mulighed for at diskutere mange almene principper bag nyhedsformidling $i$ almindelighed, $i$ billedmedieme og i DR's regi 1 sardeleshed. I eksamenslokalet kan eleven sta ved tv-apparatet og komentere indslaget, mens han spoler frem og tilbage i det. Der vil sjoldent vere brug for at spole ret meget, og teknikken volder ingen vanskeligheder, hvis man har ovet sig lidt. 
Et vigtigt trak ved eksaminationer at denne type ex at man skal vere meget forsigtig med at forlange komplette fortolkninger og skrasikre udsagn om "teksten". I mange tilfalde vil sadanne udsagn vare mere tvetydige end nar det galder en litterar tekst. Bedre ex det at lade eleven demonstrere hvilken metode han hax anvendt ved analysen og hvilke modeller han har benyttet. vd af det komner der en langt bedre situation, end den man far hvis man partout skal "afslore" mediet.

En positiv ekstra-gevinst ved denne eksamen vil vare at den spreder tilklippet og brugbart undervisningsmateriale ud over landet. Ligesom det skete med korte tekster da ulast tekst blev indfort til eksamen i Dansk.

\section{Andre fag}

Danskfaget er ikke det eneste fag hvor man $\mathrm{kan} / \mathrm{skal}$ arbejde med massekomunikation. Lad os se pa hvordan fagene er beskrevet 1 det forslag til gymnasiereform som er under behandling her 1 foraret 1987 .

I det andet store fillesfag, Historie med Samfundskundskab, ex massekonmunikation ikke et obligatorisk emne i undervisningen. Rundt om $i$ vejledningen til faget findes der inspirationer til at behandle emner med tilknytning til massekommunikation. Der næunes områder som film/video og radiomontager som eksemplex på ikke-skriftligt "fremstilingsstof" som der ogsa skal vare dele af 1 pensum, og det nævnes at et sadan fremstillingsstof kan gores til genstand for kritik. Som et eksempel navner man "TV's anvendelse af xldre optagelser til at tegne et bestemt billede af en person, en begivenhed eller en epoke". Aviser navnes stort set ikke $i$ bekendtgфrelse og vejledning, men man kan maske gå ud fra at det er en selvfolge at de benyttes ved diskussionen af nyere historie? Massekomunikationens placering og selvstanaige betydning for den moderne historie nevnes ikke. Ikke mindst i samfundskundskabsdelen af faget kunne man maske have ventet at massekommikationen blev trukket ind, men her er de obligatoriske emnex dansk politik og dansk фkonomi. 
Naturligvis er Historie med sine arbejdsmetoder med til at fremme en almindelig "kritisk bevidsthed" hos eleverne, men en egentlig "massekommunikationsbevidsthed" ex det ikke obligatorisk at arbejde med i faget.

For sprogfagene galder at man naturliquis kan arbejde med andet end "bogtekster". Man kan som grundlag for sprogundervisningen indarage radio, tv og aviser hvis man vil, men det ligger ingen steder beskrevet at man skal betragte dem under en massekommunikationsynsvinkel.

Musik bliver obligatorisk fag i. 1.9 med 3 ugentlige timer. I fagbeskrivelsen nevnes emner som musikvideoer og filmusik. Emnerne er ikke obligatoriske, men for de interesserede klasser og larere vil det vare muligt at lave et tvarfagligt samarbejde mellem Dansk og Musik. I musikvalgfaget på mellemniveauet vil sadanne emner ogsa kunne tages op, men som alle andre steder besvarliggøres de tvarfaglige muligheder af valgstrukturen.

Billedkunst bliver et obligatorisk fag i 3.9 med 2 ugentlige timer. Faget vil 1 overvejende grad blive et analytisk fag, orienteret mod kunstbilledet. Der vil dog ogsa vare muligheder for at tage "massekunst" ind, evt. i et tværfagligt arbejde, men det vil ikke vare obligatorisk.

I to valgfag vil massekommuikation indga med en vis vagt:

Samfundsfag optrader som valgfag pä mellemniveau eller hojt niveau. Pa mellemiveauet tales on "meningsdannelse og kommunikation" og på højt niveau om "socialisation og meningsaannelse", begge dele er obligatorisk. Blandt de emner man kan forestille sig her er unges medieforbrug, kommikationsteknologiens betydning, international nyhedsformiding m.m. Alt samen emner som vil gå godt i spand med Dansk, og som ogsa giver gode tvarfaglige muligheder hvis ellers de praktiske vanskeligheder kan overvindes.

Film og tv-kundskab far sin status andret med den gymnasiereform som er på vej. Fra den liat usikre tilværelse som forsфgsfag gli- 
der faget ind som et "autoriseret" valgfag pa mellemniveau. Det vil sige med fire ugentlige timer, enten i 2. eller 3.g.

Om dette $i$ realiteten betyder en større udbredelse af faget er svart at sige. Der er ingen tvivl om at det har en vis appel til eleverne, og rundt omking pa landets gymnasier findes der en del lærere med film som bifag som ikke har kinnet bruge deres udaannelse endnu. Men elevernes valg af fag er i nogen grad bundet til forskellige kombinationer, og de enkelte skoler ma desuden tage hensyn til hvad oprettelsen af et givet fag betyder for tilgangen til andre fag. Indholdsmassigt vil film- og tv-kundskab nok i nogen grad fortsatte $i$ den faglige tradition hvor filmen som kunstvark spillex en betydelig rolle, men for den massekommunikationsorientexede larer vil der vare gode muligheder for at prege faget $i$ den retning, specielt hvad angar tv-siden, og halvdelen af undervisningsforlobene skal handle on tv.

Pa de skoler hvor Film- og tv-kundskab oprettes vil der naturligvis være muligheder for et tvarfagligt samarbejde med Dansk. Da ikke alle elever pa et danskhold vil have Film-og tv-kundskab som valgfag vil den bedste form nok vare at man $i$ Dansk arbejder med nogle grundlaggende områder inden for massekomunikation. Det kunne $f x$ vare nyhedsformidling som den kan studeres $i$ aviser. Her vil man kunne give en lang række grundlaggende faraigheder, som så vil kunne bearbejdes videre i Film-og tv-kundskabs arbejde med nyheds- og aktualitetsstoffet i fjernsynet. Det vil ogsa kunne besta $i$ et grundlaggende arbejde $i$ Dansk med begreber som værdiforestillinger, bevidsthedshistorie og fortallestrukturer.

Et af de store problemer i det tvarfaglige vil vare at valgholdene vil vare sammensat af elever fra forskellige klasser, og det vil altsa krave et samarbejde mellem flere dansklarere at skabe en falles baggrund for eleverne i valgfaget. 


\section{Summa Summarum}

I det komende gymnasium vil der altsa vare et antal fallesfag hvor massekommunikation kan være et undervisningsemne, men kun $i$ Dansk vil det være obligatorisk. I valgfagene Samfundsfag og Film- og tv-kundskab vil massekommunikation vare en obligatorisk side af fagene, men ikke 1 nogen narmere fastsat malestok og altsa for en begranset del af eleverne.

Man mas se $i$ øjnene at for en stor del af fremtidens studenter vil 24-30 timer vare omfanget af den massekommunikationsundervisning de far i gymasiet.

Er det tilfredsstillende?

Claus Westh er fagkonsulent 1 Dansk for Direktoratet for Gymasieskolerne og $\mathrm{HF}$. 


\section{Hvem underviser i massekommunikation? - Hvordan? - og hvad mangler?}

\section{AP Helle Alro og Birgitte Tufte}

Disse sporgsmal har Helle Alro og Birgitte Tufte forspgt at fá besvaret ved hjelp af et sporgeskema, der blev udsendt via de fagizge forentingers blade.

Svarprocenten har indtil nu ikke veret etor, men altigevel kan de indkomne suar nok belyse tendenserne inden for medieundervisningen pá forskezlige uddannetsestmin: i folkeskolen, i gumnasiet og pa hf.

Dex står 1kke "MASSEKOMMUNIKATION" på skemaet - enanu da. Men i. de allerfleste fag er der iflg. bekendtgorelsen mulighed for at undervise i massekommuikationsemner.

Det fremgik af et seminar om massekommunikationsundervisningens status i uddannelsessystemet, som blev afholdt 1 april 86 pä foranledning af SMID. Der deltog reprasentanter for de respektive faglige foreningex inden for Folkeskolen, Gymnasiet/HF samt reprasentanter fra SMID.

Spфrgsmalet om en obligatorisk medieundervisning er blevet mere og mere presserende set i lyset af den udvikling pä medieomradet, som vi oplever $i$ disse år. Det er specielt fjernsynsudbudaet, der ekspanderer kraftigt, og det er born og unge - dvs. de uddannelsessфgende - der dominerer storforbrugergruppen af tv. 